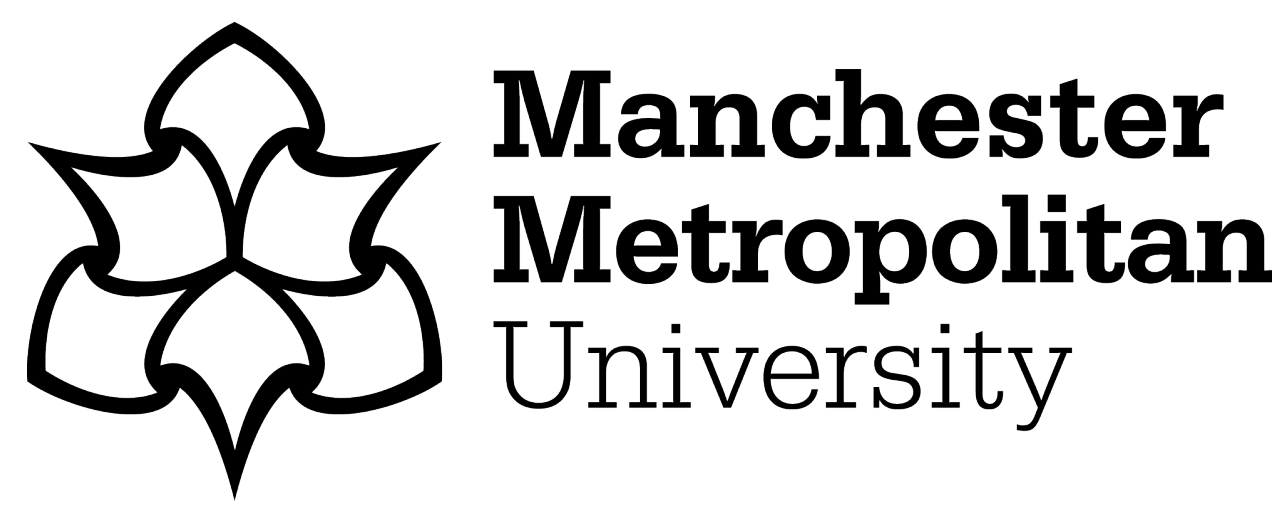

Michaelides, Zenon and Forster, Richard (2013) The Use of RFID Technologies for E-Enabling Logistics Supply Chains. In: E-Logistics and E-Supply Chain Management Applications for Evolving Business. IGI Global. ISBN 1466639148

Downloaded from: https://e-space.mmu.ac.uk/626533/

Version: Published Version

Publisher: IGI Global

Please cite the published version 


\section{E-Logistics and E-Supply Chain Management:}

Applications for Evolving Business

Deryn Graham

University of Greenwich, UK

loannis Manikas

University of Greenwich, UK

Dimitris Folinas

ATEI Thessaloniki, Greece 
Managing Director:

Editorial Director:

Book Production Manager:

Publishing Systems Analyst:

Development Editor:

Assistant Acquisitions Editor:

Typesetter:

Cover Design:
Lindsay Johnston

Joel Gamon

Jennifer Yoder

Adrienne Freeland

Austin DeMarco

Kayla Wolfe

Alyson Zerbe

Jason Mull

Published in the United States of America by

Business Science Reference (an imprint of IGI Global)

701 E. Chocolate Avenue

Hershey PA 17033

Tel: 717-533-8845

Fax: 717-533-8661

E-mail: cust@igi-global.com

Web site: http://www.igi-global.com

Copyright (C) 2013 by IGI Global. All rights reserved. No part of this publication may be reproduced, stored or distributed in any form or by any means, electronic or mechanical, including photocopying, without written permission from the publisher. Product or company names used in this set are for identification purposes only. Inclusion of the names of the products or companies does not indicate a claim of ownership by IGI Global of the trademark or registered trademark.

\section{Library of Congress Cataloging-in-Publication Data}

E-logistics and e-supply chain management : applications for evolving business / Deryn Graham, Ioannis Manikas and Dimitris Folinas, editors.

pages $\mathrm{cm}$

Includes bibliographical references and index.

Summary: "This book explores the creation of integrated supply chains, the developments of virtual business, and the processes of re-engineering for business development"--Provided by publisher.

ISBN 978-1-4666-3914-0 (hardcover) -- ISBN 978-1-4666-3915-7 (ebook) -- ISBN 978-1-4666-3916-4 (print \& perpetual access)

1. Business logistics. 2. Electronic commerce. I. Graham, Deryn, 1961-

HD38.5.E4736 2013

$658.70285--\mathrm{dc} 23$

2012051621

British Cataloguing in Publication Data

A Cataloguing in Publication record for this book is available from the British Library.

All work contributed to this book is new, previously-unpublished material. The views expressed in this book are those of the authors, but not necessarily of the publisher. 


\title{
Chapter 11 \\ The Use of RFID Technologies for E-Enabling Logistics Supply Chains
}

\author{
Zenon Michaelides \\ University of Liverpool, $U K$ \\ Richard Forster \\ University of Liverpool, $U K$
}

\begin{abstract}
This chapter reviews the potential benefits and challenges of introducing Radio Frequency Identification (RFID) technologies as a means of e-enabling logistics supply and distribution systems. It introduces RFID and associated technologies as a catalyst for e-enabling optimised supply and distribution activities. In particular, the emerging role of RFID in integrating logistics supply chains is considered key to aligning tasks and achieving operational efficiencies. Other benefits include better visibility resulting from proactive task and process management, and improved risk assessment associated with better data accuracy/quality. In addition, the optimisation of planning and control functions is enhanced through the introduction of key RFID technologies and their integration into logistics systems and operations. Finally, the use of RFID technologies is reviewed in a variety of diverse sectors and areas, from assisting humanitarian efforts through solutions aimed at recovering from the effects of natural disasters to providing accurate and effective methods of recording race times for the Los Angeles marathon.
\end{abstract}

\section{INTRODUCTION}

Logistics and supply chain management are key areas where developments in Information and Communication Technologies (ICTs) are enabling a paradigm shift in the evolution of traditional business practices. The introduction of e-logistics and e-supply chain management has brought on new challenges in the way that tasks are fundamentally assigned, executed and managed, from an operational as well as an organisational perspective. The adaptation and use of

DOI: 10.4018/978-1-4666-3914-0.ch011 
e-enabled technologies such as RFID has resulted in optimisation gains across extended logistics and manufacturing supply chains. The immediate availability of information and the dynamic nature of data enables amongst others, better visibility, more agility, more awareness, better pro-activeness and better decision support, all of which translate to higher efficiency gains. In this Chapter, we aim to introduce RFID technologies and demonstrate their positive impact on e-logistics and e-supply chain, in supporting and enabling the overall optimisation of operations management practices required to maintain competitiveness.

A historic overview of the development of RFID technologies shall be presented, and examples of key RFID applications and their use will follow. Case studies shall be presented demonstrating the challenges of introducing RFID technologies and their potential benefits.

The objective of this chapter is to critically review recent developments in the field of RFID technologies, and to discuss their suitability, adaptation and use in a variety of sectors, from production to services. The aim is to familiarize readers with the challenges associated with the various types of RFID technologies available and to present examples of their use in the fast evolving e-logistics and e-supply chain sectors. The special focus of this chapter is toidentify suitable methods of integrating the extended logistics supply chains through the use of RFID technologies, in order to enable visibility and competitiveness

On a critical note, the suitability of RFID technologies will be discussed in depth, demonstrating that RFID is not a "one size fits all" solution, rather an e-enabled approach for optimally aligning and integrating key logistics operations with a focus on sustainability and competitiveness. We will present a critical review of the literature, supporting key arguments and identifying areas of future research.

\section{BACKGROUND}

Radio Frequency Identification (RFID) is defined as a type of wireless information and communication technology, which has the ability to identify, record, verify, and process data associated with various tangible items, such as physical location of goods and the associated movement or variations thereof, as well as supporting intangible tasks, such as information processing and data execution operations associated with the provision of services.

Examples of data and information pertaining to tangible goods, which are typically captured by RFID systems are inventory quantities measured against time, date and location. Other types of measured data may include monitoring of ambient conditions, such as temperature, humidity and/ or pressure, which make the use of RFID very appealing to specific sectors, such as perishable goods and pharmaceuticals. RFID has a wide use in many diverse sectors, from retail to banking, particularly in the areas of inventory management and control, such as tracking and security. RFID is key in supporting e-logistics and e-supply chain operations through its ability to exchange information with systems such as Enterprise Resources Planning (ERP) systems. The integration of RFID with ERP systems and more recently cloud computing, offers new opportunities for enabling visibility, particularly in supply chains, where the exact location and movement of parts enables proactive planning and control, thus enhancing efficiencies and enabling competitiveness.

The roots of RFID date back to World War II and were born out of necessity to identify friendly or enemy aircraft in the air. This system, which is still in use to this day in the form of radar, was called Identify Friend or Foe (IFF). IFF used transponders placed on-board the friendly aircraft which, when interrogated by base radar stations, would return a unique code identifying them as being friendly or, in the absence of this code, the enemy. After the war, and in particular in the 1950s, 
IFF evolved further as many military spinoffs do, and is common place in both military and civil aircraft flying today (Roussos, 2008).

More applied developments of RFID took place in the 60s and 70s, primarily by the Los Alamos National Laboratory in the USA, as a means of tracking nuclear materials, and would later evolve into Electronic Article Surveillance (EAS) for controlling stock theft (Roussos, 2008). This placed an emphasis on stock control, and was the forerunner of the typical security tag operations used in many retail outlets today. During the 90s, several large-scale deployments of RFID solutions were undertaken, notably electronic toll collection in the United States and on rail cars in North America (Landt, 2005). Widespread adaptations of RFID were further driven by large retail companies, such as Wal-Mart and METRO. However, in spite of its promising potential, the successful use of RFID in e-enabling and optimising end-to-end logistics supply chains remains a challenge and has not been fully realised in recent years, suggesting that the process of RFID adaptation is more complex than previously anticipated (Ustundag, 2010).

\section{Literature Review}

There has been a significant academic interest surrounding RFID since its inception. This interest stems from the potential which RFID technologies have to redefine the way organisations traditionally identify and manage their products, and the way that they exchange information between partnering supply chain echelons. Much research attempts to identify key success factors and barriers to RFID adoption (Attaran, 2012; Charikleia 2010; Sabbaghi and Vaidyanathan, 2008). Within the literature, efficiency gains resulting from better insight and speed arising from the use of RFID technologies is discussed prolifically, with only fleeting acknowledgment of the fact that RFID might be in fact unsuitable in some instances. As a result, negative connotations to RFID are only visible in the research though the perspective of 'barriers to adaption' and not as important differentiating characteristics which could render the technology ineffective or unsuitable.

Over the years significant applied research has been conducted in the area of RFID adaptation. Such research focuses primarily on Return On Investment (ROI) through the review of several successful case studies, such as Walmart, Tesco and also the US Department of Defence (Wamaba and Boeck, 2007; Charikleia, 2010). Recently however, research has focused on the application of RFID in specific areas such as supply chain management, inventory management, logistics and transportation, assembly and manufacturing, asset tracking and object location (Sarac et al, 2009; Coltoman et al, 2008).

By comparing research conducted from an applied perspective, which details information pertaining to specific cases, to that of an academic or research perspective, which analyses theoretical benefits, there is evidence of only a limited range of positive applications which have been adapted for RFID solutions across both perspectives. These are: inventory transparency from strategic viewpoint and actual real-time inventory tracking of physical products. Specific areas of interest derived from these two points have been focused on intermittently, but rarely does RFID adaptation vary from the above areas at the fundamental level.

While these reasons are prolific and there is much consensus as to their value, they are the only factors which appear to be attracting consensus with the literature. This shows a clear disparity between the enthusiastic imaginings of the applications for RFID technology and the practical reality of its application. This suggests one of three possible concluding reasons: Firstly, that the barriers to RFID implementation are more obstructive than the widely popular opinion would suggest, despite its theoretical promise. Also, potential barriers such as cost, integration commitments and error prevention are significant enough to hamper diffusion into a diversified range of sec- 
tors. Secondly, that the benefits are not sufficiently persuasive or sufficiently well developed to influence perspective adopters to commit. Lastly, that the enthusiastic ideas of RFID proprietors have encapsulated the imagination of interested parties to the extent where this enthusiasm is causing an un-cautioned support of a technology not yet matured in its application. This idea is given further weight by Whang (2010), who suggests that early adopters of RFID have had a number of issues and that adopting a 'cautious posture' regarding this innovation may be the better ideology.

In addition to the typical barriers and success factors discussed throughout the literature, Whang (2010) discusses RFID from another important viewpoint, namely the perspective of the supplier/ buyer power relationship. Large retailers, such as Wall-Mart and Tesco have set a mandate requiring their suppliers to integrate with their RFID systems. This creates a 'free-rider' situation, where the receiving company in a supply chain can reuse the RFID tags placed upon products from the sending organisation. As a result, this affects the dynamics and places additional stress on the formation of supplier buyer partnerships.

Another disparity between the theoretical possibilities of RFID and the practical reality that arises is that most of the areas analysed throughout the literature are limited to one product, one service or one part of a business that has implemented RFID. There are very few examples within the literature of any extensive company-wide RFID implementation. The reasons are that for such a wide scope implementation, the technology is still by comparison, significantly more expensive than alternative methods. In addition, while RFID offers greater utility, alternative tracking and ID solutions such as bar-coding are still fit for purpose and remain economically attractive. With there being little research penetrating to multiple operating concerns within an organisation, it is unsurprising that the literature examining supply chain wide RFID usage is also found to be somewhat lacking. Conversely, while RFID usage is prevalent throughout 3PL companies (as well as in large organisations operating within the same supply chain) these appear to be discreet RFID implementations, joined to accommodate each other as opposed to a deliberate, coherent and homogenous set of technologies and process implemented from a strategic perspective (Sarac et al, 2009; Narsing, 2005; Ganesan, 2009).

This lack of coherence within RFID enabled systems appears to be a central theme in much of the literature. Potential reasons for this include: technological maturity, number of deployment styles, sensitivity to processes within an organisation and commitment of strategic management.

Due to the pervasive nature of RFID technologies, the adaptation and widespread use of various RFID applications has raised several concerns relating to privacy and data security. Near Field Communication (NFC) chips, essentially used in mobile phones for contactless payment and data transfer between devices, are in essence RFIDtags. However so prevalent are the security concerns regarding RFID that mobile phone organisations felt that rebranding was necessary to disassociate the term RFID from their own devices (Damgard and Pedersen, 2008; Madlmayr, 2008). This negative depiction of RFID highlights the industry's concerns with standard RFID tags, in that they offer little defence against unauthorised access. However, in supporting specific types of RFID implementations, such as in the use of NFC chips which contain sensitive data e.g. e-passports, safety measures are employed, such as encryption which can be used in conjunction with mobile phones or radio proof sheath's to prevent unwanted access in the case of e-passports.

However, in terms of RFID deployments which are typically used in supply chains, the above described countermeasures are often not practical or cost-effective to implement. In addition, a consumer privacy problem may arise if an RFID tags are not removed from items at specific intervals, such as before being shipped or sold to the public. There are two typical characteristics 
of RFID tags used in supply chains, which if not adequately monitored, have the potential to create this problem. Firstly, RFID tags are indiscriminate as to what device is reading them: their utilisation within supply chains is feasible due to the fact that tags are easy and cheap to use, and 'universal' type reading devices may be located at many points in extended supply chains. As a result of their widespread adaptation, they are unable to support any electronic countermeasures, such as those countermeasures which are present in mobile phones or laptop computers. Secondly, passive tags cannot be instructed to stop transmitting at the point of purchase. This could result in situations where either individuals or organisations acquire RFID scanners and profile specific items based on their value (Grimaila, 2007; Juels, 2005; Wang et al, 2012). The above issue remains unresolved and is further evidence of the immaturity of this revolutionary technology.

In conclusion, it seems that while RFID holds much promise, there are still a wide variety of constraints in terms of process re-engineering, external and internal integration, understanding the scale, security implications inside and outside the organisation and in considering the future of the technology within a wider contextbefore adoption.

\section{RFID in Logistics Supply Chains}

RFID may be viewed as an evolutionary successor of barcodes, but in reality RFID has unique functionality and its selection must be carefully considered. RFID can either be deployed as a stand-alone solution or could work well in conjunction with a typical barcode implementation. RFID should neither be seen as a technology that supersedes all existing barcode implementations regardless of their functionality nor viewed as the solution to all barcode shortcomings. Selection needs to be informed, with a clear understanding of the business objectives for which the required RFID implementation is sort, as well as a clear understanding of possible limitations for its use.
A comparison between RFID and Barcodes is presented in Table 1.

In its basic configuration an RFID tag comprises of an antenna and microchip, but can also include other components such as sensors (e.g. temperature) and a power source (battery, solar panel). The RFID tag contains a small amount of virtual memory that can be used to store information pertaining to an item to which it is attached. This information could be a unique identification code, e.g. part number and in addition may include other information, such as specific instructions, dates, limits, warnings, etc.

In the case of an active RFID tag, data and information are broadcast using the tags' own power source. Alternatively, for passive RFID tags, data and information can be sent as a response when the passive tag is activated within the proximity of an RFID reader. Once in communication, the reader can read the information from the tag, and update or add new information relating to the item to which the RFID tag is attached, to either the tag itself and/or to an ERP or similar system. This functionality offers a wide scope of use for RFID technology. An example of an RFID implementation is presented in Figure 1.

The RFID chip can be attached directly to a single item or to packages with a set quantity of the same item, e.g. one dozen. In addition, pallets can also contain their own RFID tag, which would record the number of packages on each pallet. This is useful for warehousing operations, including storage and location, and for integrating such information with Warehouse Management Systems (WMS). Once this chip is in the proximity of a reader, for example at the loading bay, the chip is activated and causes it to respond. The reader then relays the information to a stand-alone computer of a centralised database. This new information is then analysed and an appropriate response is generated. This response could simply be updating the status of that particular product, such as an inventory adjustment, or in the case of an unauthorised movement, sending a warning 
The Use of RFID Technologies for E-Enabling Logistics Supply Chains

Table 1. Comparison between RFID and barcodes (after: Attaran, 2012; Wamaba and Boeck, 2007; Wamaba and Chatfield, 2009)

\begin{tabular}{|c|c|c|}
\hline Factor & RFID & Barcode \\
\hline Line of Sight & RFID does not require direct line of sight. & $\begin{array}{l}\text { A bar code required direct line of sight to be } \\
\text { scanned. }\end{array}$ \\
\hline Multiplicity & $\begin{array}{l}\text { RFID can interact with a reader autonomously and therefore } \\
\text { does not require individual attention. A huge number of } \\
\text { RFID tags can pass by a reader and be processed without } \\
\text { individual attention or delay. }\end{array}$ & $\begin{array}{l}\text { A barcode scanner is required by the user to scan } \\
\text { one code at a time, delay in processing time when } \\
\text { dealing with a large volume of items. }\end{array}$ \\
\hline Capacity & $\begin{array}{l}\text { RFID's memory is limited but, depending on the design and } \\
\text { cost of the chip, can contain up to around } 1 \mathrm{MB} \text { of data. This } \\
\text { allows one tag to contain much more than a simple product } \\
\text { code. }\end{array}$ & $\begin{array}{l}\text { Barcode memory capacity is limited; in the case } \\
\text { of one-dimensional barcode it works on a similar } \\
\text { basis to Morse Code and can contain only a series } \\
\text { of numbers. In most instances this is a unique } \\
\text { identifier. }\end{array}$ \\
\hline Read/Write & $\begin{array}{l}\text { An RFID chip can read the information on this chip but also } \\
\text { amend it. This gives many powerful applications in terms of } \\
\text { monitoring expiry dates, health and safety, or even a running } \\
\text { credit system (where a chip can be credited and debited with } \\
\text { amounts) or simply augment a tally as in the case of bus and } \\
\text { train passes. }\end{array}$ & $\begin{array}{l}\text { A barcode only has the capacity to provide a } \\
\text { reader with a piece of information. This leaves its } \\
\text { function as only being an identifier. There is an } \\
\text { argument however that if readers are sufficiently } \\
\text { well equipped with software and/or Internet } \\
\text { connection then there is little advantage to being } \\
\text { able to write to a chip. }\end{array}$ \\
\hline Longevity & $\begin{array}{l}\text { In terms of passive RFID chips there is very little limit on } \\
\text { how long they can last, as they do not contain any internal } \\
\text { power source that might deplete. Active RFID chips } \\
\text { however, like those used to ascertain proximity in a } \\
\text { warehouse or shipping area, will spend their energy in time. } \\
\text { There are some innovative solutions around this, such as the } \\
\text { inclusion of a solar panel on the chip. However this is still } \\
\text { considerably more expensive and not useful in all areas of } \\
\text { application. }\end{array}$ & $\begin{array}{l}\text { A bar code can theoretically last forever, but } \\
\text { its functional constraints make this more of a } \\
\text { symptom of inadequacy rather than a testament to } \\
\text { function. }\end{array}$ \\
\hline $\begin{array}{l}\text { Environmental } \\
\text { Constraints }\end{array}$ & $\begin{array}{l}\text { One major problem with RFID is the constraints on its } \\
\text { operating conditions. Proximity to reader, proximity to } \\
\text { metal, amount of material in the way, background noise and } \\
\text { liquid all have to be considered in an RFID enabled solution. } \\
\text { This is very much dependant on the type of tag. }\end{array}$ & $\begin{array}{l}\text { A barcode has no environmental constraints. It } \\
\text { cannot be scanned through a liquid but no amount } \\
\text { of surrounding metal and or electronic noise will } \\
\text { hamper its function. }\end{array}$ \\
\hline
\end{tabular}

Figure 1. Components of basic RFID enabled system (after: IDTechEx, 2005; Veryfields, 2012; Gunther and Spiekermann, 2005)

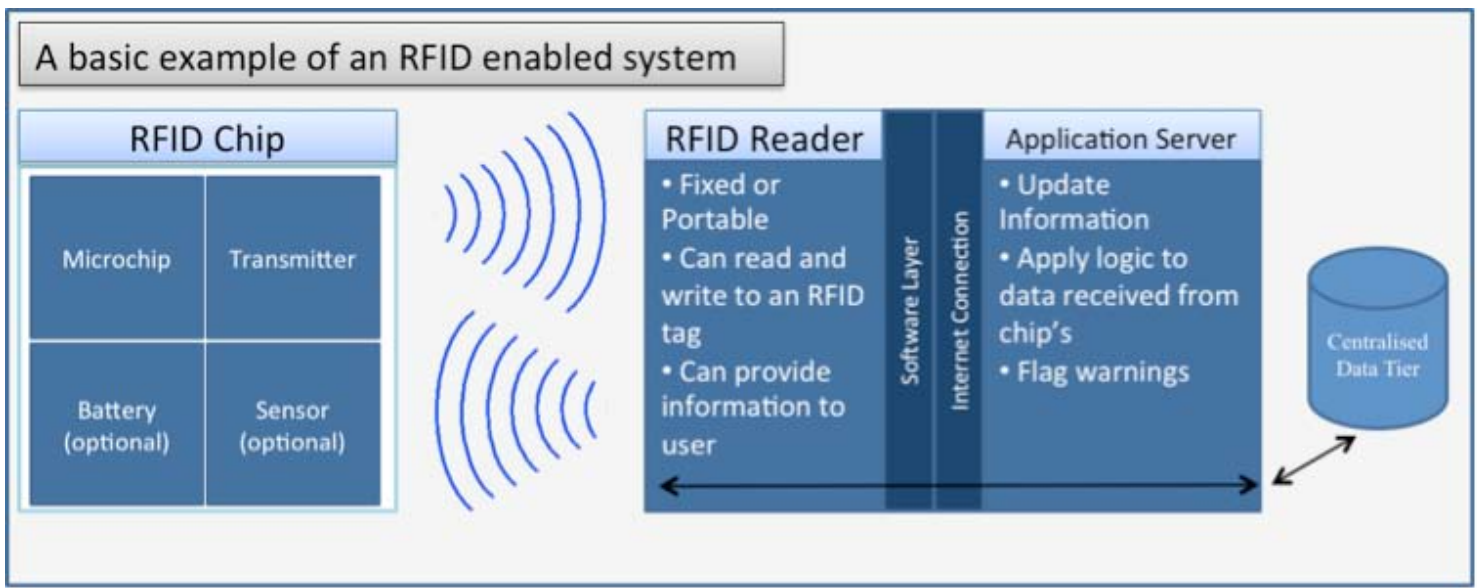


message to the reader, stating that there is no associated order for that product.

\section{RFID Tag Types}

There are many RFID tag types and various deployments that can be used depending on the particular situation on hand. The RFID tags vary significantly in terms of operating conditions, functionality and cost. Therefore, their selection must be carefully mapped to their use and the specific type of RFID tag should be considered in detail before adoption. While there are numerous types of tags, they can mostly be categorised into two broad groups: passive tags and active tags.

\section{Passive RFID Tags}

A passive RFID tag is called such because it does not actively seek to share information: it is simply activated when in proximity to a reader. It therefore does not need to contain a power source. This gives the tag far greater longevity because there is no battery integrated within it, which potentially would limit the tags' use by linking it to the battery operating life. It does however have additional constraints due to this factor, because it cannot activate itself and therefore it cannot be used to locate items. Also, the range or proximity can be challenging: depending on the frequency being used (low to ultra high frequency) the distance fluctuates substantially but never exceeds approximately 3 metres in range (Chawla 2007). That said, the most notable characteristic of passive RFID tags is that they are substantially cheaper than active tags: typically between $5 \%$ and $8 \%$ percent of the cost of an active tag.

\section{Active RFID Tags}

Active RFID tags contain batteries and because of this, they have a variety of different applications. For example, they can activate themselves which makes them useful in real time location systems
(RTLS). These are also known as 'beacon' tags, as they transmit their location intermittently. This is only made possible because the range of active tags is substantially greater. Using the onboard battery to generate Radio Frequency (RF) energy typically allows a range of $100 \mathrm{~m}$ or more, which is significant over passive tags. Additionally, the battery can be used to power other sensors attached to the tag, which can record other associated information such as temperature, humidity, pressure, etc. In addition to the substantial increase in cost, there are a further two limitations created by the inclusion of a battery, these being; the tags longevity and diversity of environments in which they can be deployed (Chawla, 2007; Weinstein, 2005).

\section{Semi Passive Tags}

There are now a multitude of hybrid tags that combine functionalities from each of the active and passive categories. A battery assisted passive tag can be thought of as essentially a passive tag that has a battery included, in order to perform additional tasks such as the powering of a temperature sensor. Their power usage is minimised through the use of an RFID tag as a power source to transmit information. Once the battery is depleted these tags stop transmitting (Jedermann, 2007).

\section{Battery Assisted Passive Tags (BAP) RFID Tags}

These are tags that contain a battery only for the purpose of assisting with the 'wake up' problem of passive tags. While a passive tag has to retain enough energy from a reader before transmitting a battery assisted passive BAP RFID tag does not. They therefore have a significantly larger range than passive tags whilst using less power than active tags which transmit there signal without using the power from the reader. Collecting power from the reader before transmitting is called the "backscatter technique." 


\section{Passive RFID Tags with Light Panel}

Passive tags can be thought of as battery assisted passive BAP RFID tags, however instead of a battery they use a small solar panel to acquire the power needed. The obvious advantage to this is that it does not having its lifespan limited by battery life, however it is also reliant on intermittent exposure to a light source or sunlight to function.

\section{RFID Tag Frequency Types}

Various frequencies can be used in order to communicate with a passive RFID tag. These frequencies have a profound effect on a number of factors, which make each one more suited to various situations. Table 2 shows the types of frequencies used for typical RFID solutions and their characteristics.

\section{RFID Implementation Challenges}

RFID technologies has been present for over 60 years, however it is only now that they are being rapidly adopted in industry and adopted on a widespread basis. There is evidence that the technology has not fully matured yet and is still developing in terms of the cost per tag and the capabilities of the system in terms of distance, interference, power acquisition. Additionally the infrastructure that support the technology is poorly developed and currently lacks a global uniform RFID standard, which gives significant challenges when attempting to integrate a number of different partners that are not committed to supply chain consistency. In firms that are largely vertically integrated, a single solution can be deployed across the entire supply chain. However, in industries where the supply chain is open there are significant issues in terms

Table 2. Types of frequencies used in typical RFID solutions and their characteristics (after: Ward and Kranenburg, 2006; Liu et al., 2010)

\begin{tabular}{|c|c|c|c|}
\hline Characteristic & Low Frequency & High Frequency & Ultra High Frequency \\
\hline Distance & $\begin{array}{l}\text { The low frequency tag has the } \\
\text { shortest operating distance of all } \\
\text { frequencies. The proximity } \\
\text { between reader and low } \\
\text { frequency tags can be around } \\
1.5 \mathrm{ft} \text { at a maximum. }\end{array}$ & $\begin{array}{l}\text { High frequency tags have a greater } \\
\text { operating distance than low frequency } \\
\text { tags with an maximum of around } 3 \mathrm{ft} \text {. }\end{array}$ & $\begin{array}{l}\text { Ultra high frequency tags have a } \\
\text { substantially larger range, a } \\
\text { maximum average of around } 10 \mathrm{ft}\end{array}$ \\
\hline $\begin{array}{l}\text { Issues with } \\
\text { Liquid and Metal }\end{array}$ & $\begin{array}{l}\text { Low frequency tags can operate } \\
\text { most effectively through liquid } \\
\text { and metal. }\end{array}$ & $\begin{array}{l}\text { Can operate though liquid and metal } \\
\text { to some extent, but can suffer from } \\
\text { the interfering effects. }\end{array}$ & $\begin{array}{l}\text { Are hugely affected by liquid and } \\
\text { water making them unsuitable for } \\
\text { many applications. }\end{array}$ \\
\hline Background Noise & $\begin{array}{l}\text { Ignores the vast majority of } \\
\text { background EM noise and can } \\
\text { operate in most conditions }\end{array}$ & $\begin{array}{l}\text { High frequency chips are a middle } \\
\text { choice, being more sensitive than low } \\
\text { frequency but not as sensitive as high } \\
\text { frequency. }\end{array}$ & $\begin{array}{l}\text { The most sensitive to background } \\
\text { noise, which can lead to a lack of } \\
\text { read ability or false reads. }\end{array}$ \\
\hline Cost & $\begin{array}{l}\text { High relative to the other two } \\
\text { options }\end{array}$ & $\begin{array}{l}\text { The price of these chips is the lowest } \\
\text { out of the three options }\end{array}$ & $\begin{array}{l}\text { Comparable with the cost of high } \\
\text { frequency chips. }\end{array}$ \\
\hline Read Speed & $\begin{array}{l}\text { The speed at which information } \\
\text { can be transferred between tag } \\
\text { and reader is slowest with low } \\
\text { frequency tags. }\end{array}$ & $\begin{array}{l}\text { High frequency offers a greater read } \\
\text { speed than low frequency, not as } \\
\text { much as ultra high }\end{array}$ & $\begin{array}{l}\text { Provides the greatest read speed } \\
\text { of all passive tags. }\end{array}$ \\
\hline Typical Applications & $\begin{array}{l}\text { - Point of Sale } \\
\text { - Vehicle immobilisers } \\
\text { - Healthcare application } \\
\text { - Product Authentication } \\
\text { - Animal tracking }\end{array}$ & $\begin{array}{l}\text { - Smart Cards } \\
\text { - Smart Shelves } \\
\text { - Library books } \\
\text { - Healthcare Patients } \\
\text { - Airline baggage }\end{array}$ & $\begin{array}{l}\text { - Supply chain functions } \\
\text { - Electronic Product Code } \\
\text { - Electronic Toll Systems } \\
\text { (Motorway) } \\
\text { - Parking lot access }\end{array}$ \\
\hline
\end{tabular}


of compatibility of infrastructure as well as with the cost of the significant middleware requirements (Chan et al, 2012). This can be seen in Figure 2.

In an open supply chain set-up, where various supply chain echelons will be servicing several clients, no prescription exists that each of these clients will be using the same RFID systems. Indeed is likely that the same solutions will not be suitable to support the different functions required by the various parties involved. Therefore, as shown in Figure 3, each retailer RFID generated data will be entered into their respective ERP systems via a piece of middleware, the purpose of which is to facilitate integration. Their ERP information will then be sent to the suppliers system via the Internet. If the retailer wishes to promote total transparency, then the RFID codes and tags will be placed onto the products at the distributor level. This will require the use of different tags for each retailer, depending on their own requirements. In addition, it shall require a different piece of middleware in order to integrate the RFID tag with distributors own ERP system. It is probable that the distributor shall need to have the ability read the incoming RFID tags from the suppliers, thus requiring yet another set of readers and middleware. This is costly and undesirable, and it is likely that firms who wish to benefit from supply chain transparency and RFID efficiency will need a consolidated effort, which in itself presents huge challenges. It is therefore clear that in each situation where RFID is being considered as a solution, a full return on investment analysis should be carried out to assess the total cost of integration with existing company data structures as well as the data structures used in by value chain partners. This is a current drawback of RFID in that it can rarely be considered an addition to current systems and often requires redesign of exiting processes (Angeles, 2005).

Figure 2. Integrating RFID in an open supply chain (after: Narsing, 2005; Wamaba \& Boeck, 2007)

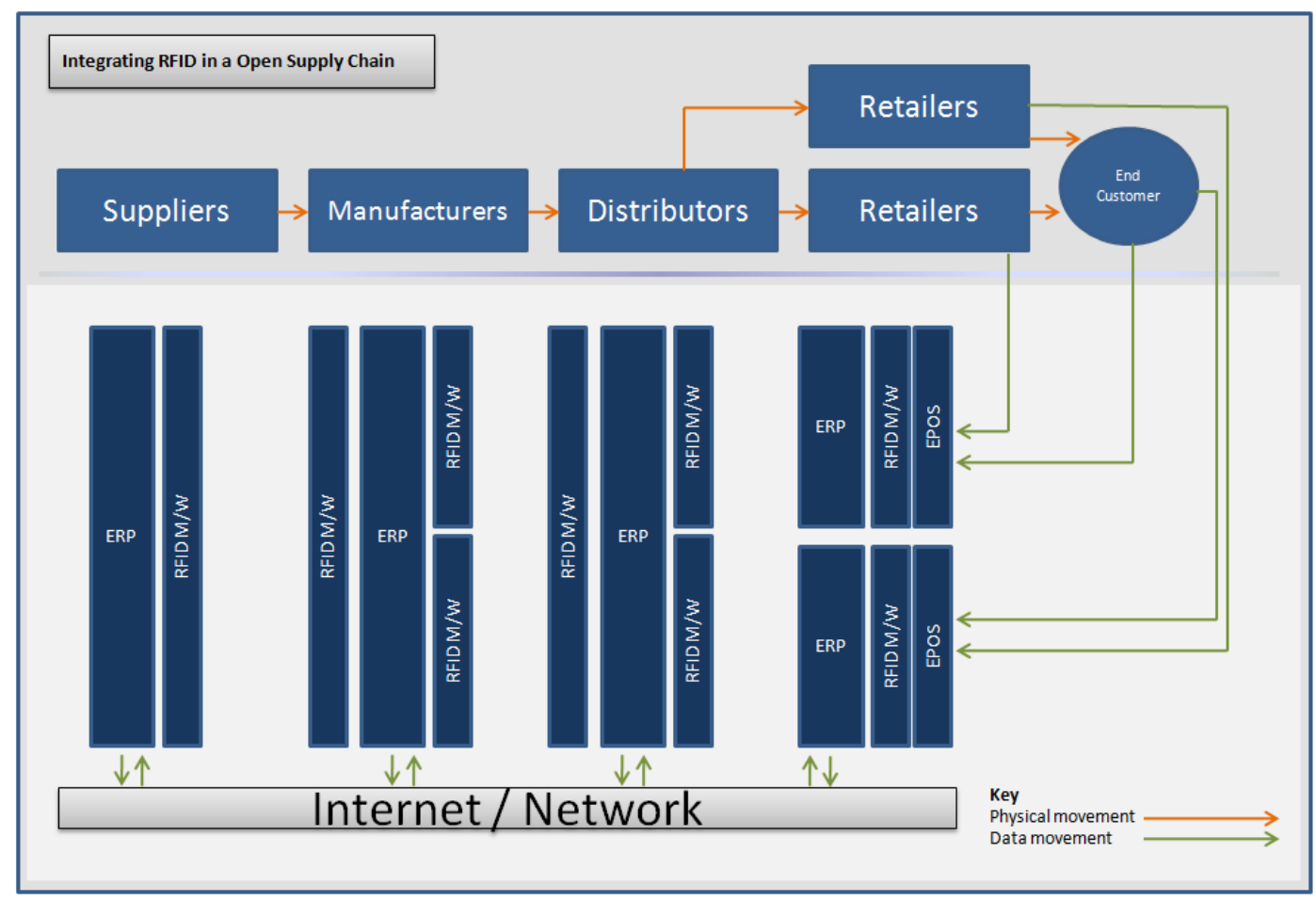


Figure 3. RFID in logistics supply chain system

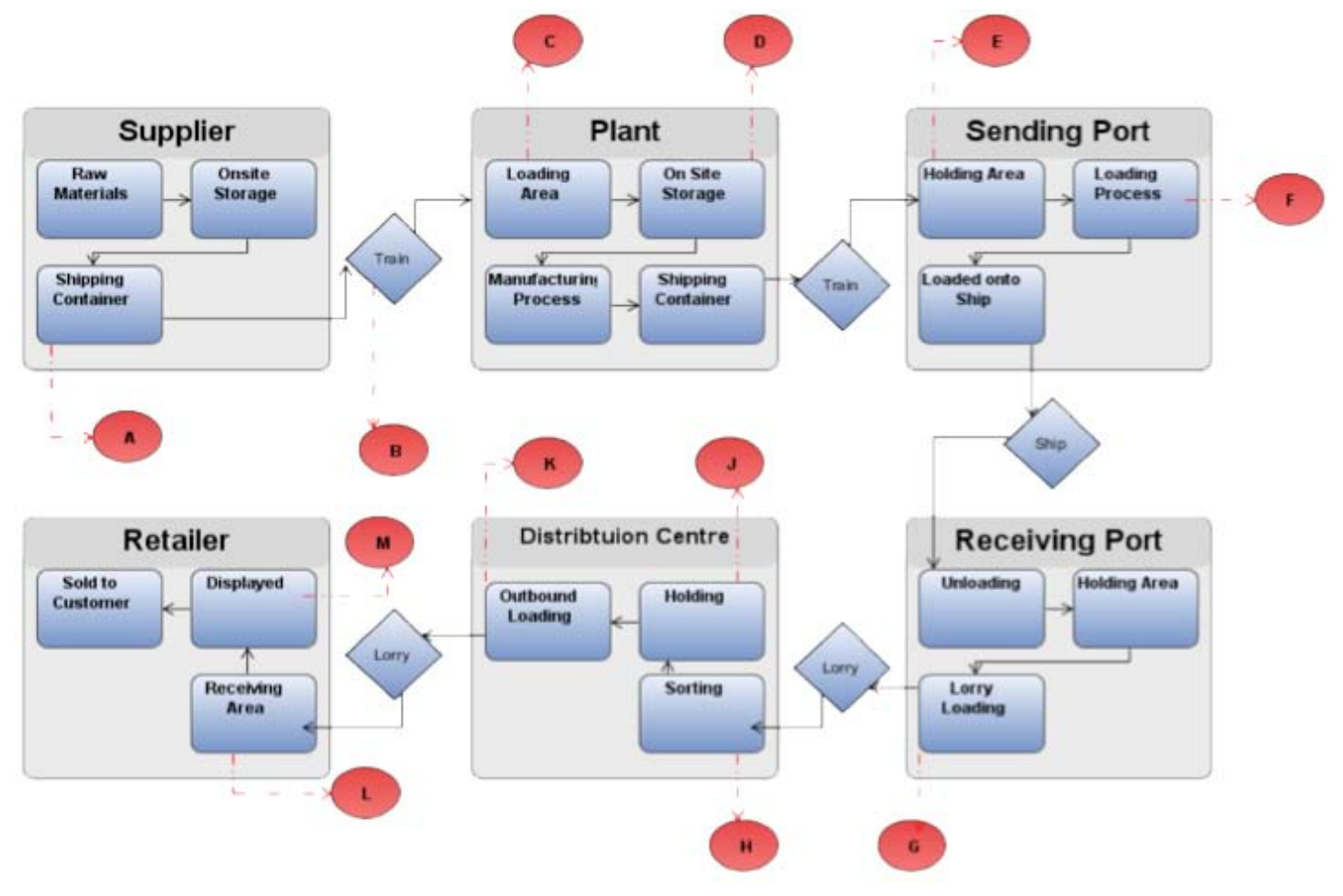

The future will require a standardised set of RFID technologies that offer interoperability between readers and tags for all stakeholders across extended supply chains.

\section{Cost Related Challenges}

While RFID technologies are steadily coming down in price they are currently still relatively expensive. The total cost is also relatively difficult to consider as it depends on the deployment design, how many passive tags are needed, how many active tags, type of active and passive tags, special sensor requirements, number of readers, amount of data required to be exchanged, operating conditions etc. Cost has long been a significant factor in deterring potential investors from investing in the technology and this seems likely to continue to be true (Michael and McCathie, 2005). The complicated pricing of the technology as well as the lack of maturity and standardisation may understandably make potential investors nervous about using RFID.

\section{Reliability Challenges}

There are numerous reliability issues surrounding RFID, which need to be considered in any RFID deployment. Passive tags for example take time to charge in order to acquire the energy to return a signal. Higher frequency tags charge faster but are very poor at signalling thought water or metal. Tags with a power source could cause potential disturbance of processes if the battery fails at a key moment. All of these issues must be considered in order to address the individual needs of RFID users whilst taking each specific deployment into consideration based on its characteristics and idiosyncrasies (Mishra et al, 2012; Derakhshan et al, 2007). 


\section{Data Challenges}

It is not unusual for a reader to be able to interact with 800 or more RFID tags in a second and with the increased memory on the tags the demand on virtual storage is significant. Wal-Mart suggested that RFID generates 7.5 terabits of information per day. The volume of information places extra demands on hardware and software to be able to extract the desired information. There may also be unnecessary and misleading information generated by an RFID system e.g. when a member of staff moves an item to simply let something past or if a customer changed what shelf an items was on. This volume of data will require some element of redesign in terms of both the process mapping and software deployment used to extract business intelligence from operational data.

\section{RFID IN LOGISTICS AND SUPPLY CHAINS}

There are many examples of RFID solutions in logistics and supply chain sector. RFID is particularly suited due to its ability to track and control inventory movements and control the location of stocks.

Figure 3 is a typical supply chain process, whilst viewing the roles of RFID in logistics. These functionalities are based on actual cases used in international logistics companies such as DHL and FedEx.

Process A: The supplier, of what in this instance are raw materials, has to transport these materials from their facility to the manufacturing plant. In order to do this they are loaded into standardised shipping containers. If we assume that the materials are palletised before placing them into a container, then there are multiple opportunities for RFID use on offer. Since these are raw materials it is likely the value is reasonably low. We will therefore assume these items are potentially not worth tagging individually. Instead, the pallets and containers are tagged. Pallets with passive ID tags can be loaded and the tags programmed. These pallets can then be loaded into a shipping container in proximity to RFID reader, which will feed back information on weight, approximate value and time of loading through the Internet into a centralised database.

Process B: These shipping containers are to be loaded into a train. When the tagged pallets where placed into the container they became associated with that specific container in the ERP system. Each of the containers also has a tag and while the passive tags on the pallets cannot be scanned through the metal container their contents are known. The ERP system already lists the approximate weight of each of these containers, pallets and the associated value. This can guard against theft and aid the supplier's case for reliability by having each container weighed when it gets to its destination.

Process C: Once at the manufacturing plant the containers can be off-loaded from the train and scanned. It is possible that the container scanners can be fitted with a movement sensor to detect the likelihood of damage to the materials due to shifting, in order to aid in quality control. In the event that there has been significant movement to the products, they can undergo an inspection and be send back without wasting time unloading.

Process D: Once the pallets have been removed from the train they can be placed in site storage though an RFID reader, which can detect the nature of the contents of each pallet. This information can instantly be fed back to the handler to instruct them where in the storage area the pallets should go. For example, if they are in short supply they may be required immediately; if they are hazardous special precautions can be adhered to. 
Process E: After the manufacturer has produced, palletised and added to a shipping container, the new products can be sent to a shipping port for distribution. Each major shipping port has used RFID technology for a number of years in increasingly diverse ways. Shipping ports do not belong to one supply chain alone, and have a huge volume of containers present in any given time. In order to effectively locate each of these containers, each of the containers or indeed pallets can contain active RFID beacon tags that intermittently broadcast there location. Therefore also helping to efficiently manage and control all the items on the site.

Process F: When loading the shipping containers it is appropriate to consider weight distribution, weight sensors attached to an active RFID tag on each of the container will allow appropriate allocation of weight on the ship itself. Once again, all containers are read by readers as they are loaded. This information can be fed back to the expecting customer, allowing them to plan resources such as lifting equipment or manpower and expertise, thus enabling pro-activeness and maintaining supply chain visibility.

Process G: After processing at the receiving port, the containers will be loaded onto transportation vehicles. The arrival time of each product can be automatically updated. The distribution centres most in need of the products can beidentified by the ERP system, in order to determine the order of delivery and to track any change in delivery method or process. DHL have labelled this kind of automated RFID-enabled recalculation of product logistics as 'The Internet of Things' since the products are effectively informing their destination depending on time, market demand, potential damage, etc.

Process H: Logistics has a long-standing issue with the time delay in sending goods the 'last mile', which is a term used to identify the final stages of delivery of a product to a customer. Using on-line shopping as an example, it can be seen that the international shipping process is arguably more efficient than the regional Distribution Centres (DCs) complex system deliveries. RFID can offer a solution for the above by having the items scanned into the DCs in bulk without the need to laboriously scan each of the bar codes. The functionality offered by movement sensors in quality control can also have a profound impact here.

Process J: When products have been entered in a DC, there can be multiple RFID readers in order to track movement and order progress. These status updates give greater transparency both internally and supply chain wide, such as low stock levels, in order to tackle the problem of stock-outs. This also does not slow down the processes within the DC because RFID requires no manual involvement beyond initial installation, or line of sight between product and scanner.

Process K: Outbound loading in a DC is made easier with RFID. Having the RFID readers either at the outbound loading station or actually in the vehicles themselves allows an efficient and non-laborious loading process. In addition, having portable RFID scanners in the vehicle offers added opportunities to monitor goods in transit, particularly if they are perishable, subject to heat damage or if there is potential for damage caused by driving. The goods can return to the DC, without undergoing the process of delivery, rejection, and return.

Process L and Process M: There is a drive by proprietors of RFID technologies and some prominent retail industry players to have RFID tags moved from the logistics equipment and onto the products themselves, totally replacing barcodes. This would allow dramatic application for both the supply chain and the customer. A customer could 
pick up a product with an RFID tag from a 'smart shelf' and the shelf could then display the price, expiry date, offers involving the product etc. If the product is not replaced the system can deduct this item from the in-store inventory and inform the stock area thought theERP system regarding re-supply. Finally, all items could be simultaneously scanned at the checkout by RFID readers.

Eventual integration with NFC (near field communication) chips in phones, which is being perused by Nokia, could simply allow customers to enter a store, pick up items and leave the store. All payment could be automated through RFID and the mobile phone. Biometrics could be incorporated into the phone for a more secure system. The potential for the technology is clearly extensive, with the RFID cost dropping and contactless infrastructure growing, the possibly of these seemingly science fiction style applications are coming a more viable option.

\section{Case Studies: RFID in Logistics}

The following section discusses several case studies presented by the Association for Automatic Identification and Mobility (AIM) (2012), which implemented a number of RFID solutions in various sectors. Each case study is described and summarised in Table 3 by presenting suitable scenarios detailing the specific challenges faced by each company and the RFID solutions implemented.

Case Study 1 (Griva Textiles): Italian Textile Firm. (Access to full case study at http:// www.aimglobal.org/members/news/ articlefiles/3361-CS_Alien-Griva.pdf). Griva Textiles is a high-volume textile manufacturer. Their biggest challenge was managing inventory through each production stage and introducing an RFID solution to manage the manufacturing and distribution process, from raw materials to finished product.

Case Study 2 (The State of Texas, US): (Access to full case study at http://www.aimglobal. org/members/news/articlefiles/3454-CS_ motorola-StateofTexas.pdf). This case addresses the challenges faced by the State of Texas when addressing the effects of natural disasters and describes how RFID played a key role in assisting the humanitarian efforts that arose as one million people evacuated from Hurricane Katrina in August 2005 and more than 2.7 million people fled from Hurricane Rita the following month. The solution includes an RFID automated evacuee tracking system using wrist bands.

Case Study 3 (McCarran International Airport): (Access to full case study at http://www.aimglobal.org/members/news/ articlefiles/3456-CS_motorola-McCarran_ Intl.pdf). McCarran International Airport is the 7th busiest airport in the USA, and handles nearly 70,000 passengers and over 460 flights daily. The airport has experiences a large growth in passenger numbers primarily due to its proximity to the popular city of Las Vegas and its resorts. To meet such high demand, the airport introduced an RFID solution to manage passenger's baggage.

Case Study 4 (American Apparel Clothing): (Access to full case study at http://www.aimglobal.org/members/news/articlefiles/3457CS_motorola-American_Apparel.pdf).

American Apparel is a leading retailer with a unique selling point: they stock only one item of each style, colour and size on the shop-floor at any time. This makes inventory management challenging for its manufacturing, distribution and retail operations, and relies on RFID to provide accuracy in ensuring minimising out-of-stock situations.

Case Study 5 (Southeastern Container Company): (Access to full case study at http://www.aimglobal.org/members/news/ 
The Use of RFID Technologies for E-Enabling Logistics Supply Chains

Table 3. Analysis of RFID case studies

\begin{tabular}{|c|c|c|}
\hline Case & Scenario & Benefit \\
\hline $\begin{array}{l}\text { Griva Textile } \\
\text { Company } \\
\text { (AimGlobal, 2012) }\end{array}$ & $\begin{array}{l}\text { Griva an Italian textile company had previously been identifying } \\
\text { their rolls of material with barcodes at the base. The fabric is } \\
\text { exposed to chemicals and harsh temperatures as a method of } \\
\text { quality control. This often destroyed the barcode and made a } \\
\text { chaotic environment to attempt the kind of highly controlled } \\
\text { inventory management that the industry demands. }\end{array}$ & $\begin{array}{l}\text { Griva contacted a RFID enabling company } \\
\text { called Simet. With the use of highly durable } \\
\text { passive tags from Alien Technologies, Simet } \\
\text { succeeded in replacing the existing barcode } \\
\text { system, solving the problem of harsh environ- } \\
\text { ment and integrated the information in real } \\
\text { time with their current ERP thought a bespoke } \\
\text { development of middleware. }\end{array}$ \\
\hline $\begin{array}{l}\text { The State of Texas } \\
\text { (AimGlobal, 2012) }\end{array}$ & $\begin{array}{l}\text { The state of Texas was flooded with over } 450,000 \text { refugees after } \\
\text { Hurricane Katrina hit the southern coast of America, } 145,000 \\
\text { of these had no identification whatsoever. It became clear that } \\
\text { current methods of dealing with the refuges where ineffective as } \\
\text { families where separated and the logistical and housing } \\
\text { confusions that arose cost the state a large amount of money. }\end{array}$ & $\begin{array}{l}\text { The head of state contacted Motorola and a } \\
\text { number of partner companies to help solve } \\
\text { this by using RFID. The state now has RFID } \\
\text { wristbands that will be given to refugees } \\
\text { and associated family members stored in the } \\
\text { database. All emergency vehicles and public } \\
\text { transport such as busses have been fitted with } \\
\text { GPS tracking and an RFID reader. Readers } \\
\text { can also be found at all designated Refugee } \\
\text { centre. This allows the state authorities to track } \\
\text { individuals and traffic, and resource } \\
\text { requirements across state }\end{array}$ \\
\hline $\begin{array}{l}\text { McCarran } \\
\text { International } \\
\text { Airport } \\
\text { (AimGlobal, 2012) }\end{array}$ & $\begin{array}{l}\text { This airport located in Las Vegas is the } 7^{\text {th }} \text { largest airport in the } \\
\text { world with } 70,000 \text { passengers and } 460 \text { flights each day. } \\
\text { McCarran International Airport has experienced growth into } \\
\text { double digits for the past few years due to the increased } \\
\text { popularity of Las Vegas to tourists' hot spot. This had lead to } \\
\text { the processes in place being overwhelmed and unable to scale to } \\
\text { meet the increased demand. A particular issue was the airports } \\
\text { poor effeminacy record with baggage. }\end{array}$ & $\begin{array}{l}\text { Motorola was contacted to solve the issue. Low } \\
\text { cost passive disposable RFID tags are fitted } \\
\text { to the baggage upon check-in and a series } \\
\text { of RFID reader along the conveyer system } \\
\text { directs the luggage to either a scanner, detailed } \\
\text { inspection department or the relevant plane } \\
\text { depending on the information contained on the } \\
\text { RFID tag. The airport has reported near 100\% } \\
\text { accuracy rating with reference to their baggage } \\
\text { handling since the implementation. }\end{array}$ \\
\hline $\begin{array}{l}\text { American Apparel } \\
\text { Clothing } \\
\text { (AimGlobal, 2012) }\end{array}$ & $\begin{array}{l}\text { American Apparel are a large clothing manufacturer in the US. } \\
\text { They were suffering losses from excessive internal shrinkage due } \\
\text { to internal theft and processing errors ( } 60 \% \text { of total shrinkage). } \\
\text { They are heavily vertically integrated and system wide } \\
\text { transparency had significant potential to affect profits in the } \\
\text { origination and theirself-controlled supply chain. }\end{array}$ & $\begin{array}{l}\text { American Apparel introduced a supply chain } \\
\text { wide RFID system to control all assets with the } \\
\text { chain. This involved scanners and tags in the } \\
\text { textiles plant thought to the distribution centre. } \\
\text { The result of this was a 55\% reduction in total } \\
\text { shrinkage. }\end{array}$ \\
\hline $\begin{array}{l}\text { Southeastern } \\
\text { Container } \\
\text { Company } \\
\text { (AimGlobal, 2012) }\end{array}$ & $\begin{array}{l}\text { The Southeastern Container Company produces more than } 70 \% \\
\text { of the bottles for Coca-Cola in the US. In } 2012 \text { they changed the } \\
\text { container used to transport there product from a of the shelf } \\
\text { disposable plastic container in favour of a bespoke hard plastic } \\
\text { bin that was designed to carry more of their product in a safer } \\
\text { way. The problem however was that they already suffered } \\
\text { significantly from damage and loss of other non-disposable } \\
\text { containers used and given that the bins where ten times more } \\
\text { expensive than any of the containers currently used. }\end{array}$ & $\begin{array}{l}\text { In order to prevent this each of the containers } \\
\text { was fitted with an active RFID chip to } \\
\text { intermittently broadcast its location on site. } \\
\text { They reduced their shrink rates hugely and } \\
\text { expect a return on investment by } 2014 \text {. }\end{array}$ \\
\hline $\begin{array}{l}\text { Log Angeles } \\
\text { Marathon } \\
\text { (AimGlobal, 2012) }\end{array}$ & $\begin{array}{l}\text { The Los Angeles Marathon attracts over } 12,000 \text { runners at each } \\
\text { event. Large numbers of participants crossing the finishing line } \\
\text { at the same time posed issues in associating timings to all of the } \\
\text { participants. }\end{array}$ & $\begin{array}{l}\text { By simply placing an RFID scanner inside the } \\
\text { finishing line itself and attacking inexpensive } \\
\text { RFID tags to each of the runners' armbands } \\
\text { the organisers managed to achieve a } 98 \% \\
\text { success rate and save considerable amount of } \\
\text { money when pared to any other system that } \\
\text { could deliver that level of accuracy. This is a } \\
\text { good example of how RFID can be used for a } \\
\text { diverse range of industries }\end{array}$ \\
\hline
\end{tabular}


articlefiles/3500-CS_motorola-SoutheasternContainer.pdf). Southeastern Container handles nearly $70 \%$ of the bottle production for Coca-Cola in the U.S., and introduced an RFID system to provide an end-to-end solution designed to address inventory control and traceability for specialized product containers. This solution, which was designed to work in association with existing barcode systems, involves approximately 30,000 bins, which will be permanently identified with an RFID tag and their locations tracked to minimise losses.

Case Study 6 (Los Angeles Marathon): (Access to full case study at http://www. impinj.com/Documents/Applications/ Case_Studies/LA_Marathon_Event_Timing_Case_Study/). The innovative solution was aimed at supporting the popular Los Angeles Marathon, which is the USs fourthlargest, with 20,000 participants and 12,000 race day volunteers. The solution provided an accurate and effective way of recording race timings, which is challenging particularly when large numbers of participants cross the finishing line simultaneously. The solution provided RFID tags integrated into runner's bibs, which is a piece of material used to display a runner's number and association or attached to their running shoes.

\section{CONCLUSION}

This chapter has introduced RFID as a viable tool and contemporary solution in the areas of e-logistics and e-supply chain management. The historic evolution of RFID has been presented, detailing how early advances in radar technologies helped to develop the key functionality behind RFID. The ongoing evolution of RFID, from the research environment to an applied solution in the real world, has further focused its requirements and offered new directions for its potential use.
The recent widespread adaptation of RFID across various sectors has raised awareness of this technology, as well as questions relating its ability to meet contemporary challenges. The effectiveness of RFID in certain types of applications and under certain scenarios is undisputed. This can be seen from the case studies, where the benefits of adapting RFID solutions are clearly demonstrated. However, evidence also suggests that RFID should not be seen as the 'panacea' for all problems, and selection of this technology should be made on an informed basis, with a clear understanding of both its abilities as well as its limitations. This can be done by reviewing the objectives and business benefits for each prospective deployment against the technical, operational and cost implications. For example, under some conditions the use of RFID may be possible as a long-term solution, but not viable on the grounds of cost-effectiveness. In this case barcodes may be a more suitable solution, due to their lower cost of implementation.

RFID has proved to be a valuable tool supporting operations across extended e-logistics supply chains, through its ability to track, monitor, control and manage the movement of goods and associated processed and services. RFID has enabled efficiency gains, optimised and indeed changed the way that certain practices are traditionally carried out, such as inventory management. Due to their versatility and ability to integrate with other systems, such as Enterprise Resources Planning (ERP) systems and Global Positioning Systems (GPS), they have enabled goods tracking on a global scale. In the process RFID has demonstrated tangible cost benefits, such as reducing losses due to pilferage, theft, etc. and optimised e-supply chains by enabling better visibility.

RFID is at the forefront of technologies supporting many different types of logistics operations, such as humanitarian logistics, e.g. disaster relief. In addition, RFID increasingly plays a key role in conservation projects, from wildlife tagging e.g. studying migratory habits of animals, to the preservation of antiquities, e.g. recording of 
artefacts. As RFID matures further, it finds additional uses in many diverse areas, from controlling the movement of perishable items to monitoring of donor organs. RFID continues to offer a way forward in effectively recording and monitoring an increasing array of parameters, and is being integrated into a number of products aimed at, amongst others, offsetting counterfeiting such as e-Passports, and supporting effective decision making processes. The adaptation of RFID will undoubtedly increase as its costs of acquisition decrease and its use and application of its technologies find new ground.

\section{Further Research}

Future research in this area revolves around exploring the potential of Low Field magnetic autoIdentification technology, known as 'RuBee,' as a potential alternative, replacement or accessory to RFID. In many respects the technology would appear to mimic the functionality of RFID; however it has a number of differing characteristic that alter its potential application. RuBee, like Active RFID systems, consists of a tag that contains an antenna, battery and a small amount of data storage that can be read and written to by a reader. (Mishra et al, 2012).

The similarities however end there. Instead of high frequency radio waves, RuBee uses long wavelength microwaves and requires a cheaper yet potentially more physically intrusive reader. Unlike RFID, the RuBee reader utilises a long loop antenna and all tags must be contained within or close to the limits of this loop. These antennas add the undesirable requirement of having to precisely plan the area to be scanned; however, they can often be concealed in ceiling floors and are less expensive than the readers associated with their RFID counterparts (Chiu, 2010).

In addition to the infrastructure, the usage characteristics also differ: the long wavelength of RuBee means that the technology can operate irrelevant of surrounding water, metal or elec- tromagnetic interference-indeed steel is shown to actually boost the signal. This makes that the technology is far superior to Radio based autoidentification systems, such as RFID, in many applications, circumstances and environments. A few examples include: the mining industry which has an existing requirement for auto identification of explosives in an underground setting (Mishra et al, 2012), in hospitals where current equipment typically produce a significant amount of electromagnetic interference (Kapa et al, 2012) or within logistics and distribution, to locate items amongst the large volume of metal found in the shipping containers or shelving units.

RuBee technologies also differ from RFID in that they are predominately active tags that contain a power source. Whilst this does give the tags an eventual expiry date, the low wavelength used results in a lower power usage rate, with a battery being able to last 10-15 years, essentially mitigating this draw back in many potential instances of RuBee utilisation (Jolluck and Weich, 2010). The nature of the technology and its low power usage allows RuBee to operate peer-to-peer, i.e. tags can communicate information and logic between them. This characteristic facilitates a significant number of innovative auto ID applications, such as the RuBee tag on a car being able to tell if the RuBee tag on the engine or wheels have changed. Another example is in aircraft, where a Rubee tag attached to a particular part could hold information pertaining to the last maintenance of that specific part. This tag could communicate with one in the cockpit that disallows take off until a certified mechanic with a certified reader has cleared the part.

RuBee technologies do however have significant drawbacks compared with RFID. Typically RuBee tags are more expensive and the long wavelength leads to a slow data transfer rate which would make it incapable of processing a large number of tags at speed. This would invalidate the technologies usefulness in scenarios that require high speed data transfer, such as a cross docking 
depot or a supermarket receiving a large number of concurrent deliveries (Stevens et al, 2010).

That fact that RuBee tags can utilise larger volumes of data on the tag and interact peer-topeer has led to RuBee being dubbed a 'visibility tool' rather than a 'tracking tool', for use when exact location and absolute visibility is required. The two auto-identification technologies seem to significantly overlap but fundamentally fulfil different functions. It therefore seems highly unlikely RuBee will replace RFID. Neither one completely replicates the utility of the other, which suggests that the future will possibly see hybrid deployments of the two technologies mediated by a centralised computer system. What is subject to future research is the manner in which these technologies will evolve and how they will precisely manifest.

\section{REFERENCES}

AIM. (2012). RFID cases. Retrieved July 02, from http://www.aimglobal.org/casestudies/RFID.asp

Angeles, R. (2005). RFID technologies: Supply chain applications and implementation issues. Information Systems Management, 22(1), 51-65. doi:10.1201/1078/44912.22.1.20051201/85739.7

Attaran, M. (2012). Critical success factors and challenges of implementing RFID in supply chain management. Journal of Supply Chain and Operations Management, 10(1), 144-167.

Chan, C.-K., Chow, H. K. H., Ng, A. K. S., Chan, H. C. B., \& Ng, V. T. Y. (2012, March). An RFID case study for air cargo supply chain management. Paper presented at the International Multi-Conference of Engineers and Computer Scientists. Hong Kong, China. Retrieved from http://www.iaeng.org/publication/IMECS2012/ IMECS2012_pp278-283.pdf
Charikleia, L. (2010). RFID in the retailing supply chain: A case study on fashion retailing industry. (Masters Dissertation). Retrieved June 20, from https://gupea.ub.gu.se/bitstream/2077/22606/1/ gupea_2077_22606_1.pdf

Chawla, V. (2007). An overview of passive RFID. IEEE Communications Magazine, 45(9). Retrieved from http://ieeexplore.ieee.org/xpls/ abs_all.jsp?arnumber=4342873 doi:10.1109/ MCOM.2007.4342873

Chiu, B. (2010). Leveraging visibility technology for business applications. Oracle White Paper. Redwood Shores, CA: Oracle Corporation.

Coltoman, T., Hadh, R., \& Michael, K. (2008). RFID and supply chain management: Introduction to the special issue. Journal of Theoretical and Applied Electronic Commerce Research, 3(1).

Damgard, I., \& Pedersen, M. (2008). RFID security: Trade-offs between security and efficiency. Computer Science, 4964, 318-334. Retrieved from http://www.bytopia.dk/blog/wp-content/ uploads/2008/08/rfid.pdf

Derakhshan, R., Orlowska, M., \& Li, X. (2007). RFID data management: Challenges and opportunities. In Proceedings of the IEEE International Conference on RFID, (pp. 26-28). IEEE Press. Retrieved from http://130.102.79.1/ xueli/IEEERFID-Conf-04143527.pdf

Ganesan, S., George, M., Jap, S., Palmatier, R., \& Weitz, B. (2009). Supply chain management and retailer performance: Emerging trends, issues and implications for research and practice. Journal of Retailing, 85(1), 84-94. doi:10.1016/j. jretai.2008.12.001

Grimaila, M. (2007). RFID security concerns. ISSA Journal. Retrieved from https://dev.issa.org/ Library/Journals/2007/February/Grimaila\%20 -\%20RFID\%20Security\%20Concerns.pdf 
Gunther, O., \& Spiekermann, S. (2005). RFID and the perception of control: The customers view. Communications of the ACM, 48(9), 9. doi:10.1145/1081992.1082023

IDTechEx. (2005). An introduction to RFID and tagging technologies. Retrieved June 30, from http://www.idspackaging.com/Common/Paper/ Paper_486/Y9268U8423.pdf

Jedermann, R. (2007). Semi-passive RFID and beyond: Steps toward automated quality tracing in the food chain. International Journal of Radio Frequency Identification Technology and Applications, 1(3). Retrieved from http://www.sfb637. uni-bremen.de/pubdb/repository/SFB637-B6-07026-IJ.pdf doi:10.1504/IJRFITA.2007.015849

Jolluck, D. \& Weich, C. (2010). An oracle white paper: An introduction to rubee technology. Oracle White Paper. Redwood Shores, CA: Oracle Corporation.

Landt, J. (2005). The history of RFID. IEEE Potentials, 24(4), 8-11.doi:10.1109/MP.2005.1549751

Liu, L., Chen, Z., Yan, D., Lu, Y., \& Wang, H. (2010, May). E-business and e-government. In Proceedings of the ICEE 2010 International Conference, (pp. 2379-2382). IEEE.

Madlmayr,G.(2008).NFCdevices:Securityandprivacy. Retrievedfrom http://ieeexplore.ieee.org/xpl/ login.jsp?tp $=\&$ arnumber $=4529403 \& u r l=h t t p \% 3$ A\%2F\%2Fieeexplore.ieee.org\%2Fxpls\%2Fabs_ all.jsp\%3Farnumber\%3D4529403

Michael, K., \& McCathie, L. (2005). The pros and cons of RFID in supply chain management. In Proceedings of the International Conference on Mobile Business, (pp. 623-629). Retrieved form http://ro.uow.edu.au/cgi/viewcontent.cgi article $=1104 \&$ context $=$ infopapers $\&$ sei-redir $=1 \&$ referer $=$ http $\% 3 \mathrm{~A} \% 2 \mathrm{~F} \% 2 \mathrm{Fschol}$ ar.google.co.uk\%2Fscholar\%3Fq\%3DRFID \%2Bc ost $\% 2 \mathrm{Bmanagement} \% 26 \mathrm{btnG} \% 3 \mathrm{D} \% 26 \mathrm{hl} \% 3 \mathrm{Den}$ $\% 26$ as_sdt $\% 3 \mathrm{D} 0 \% 252 \mathrm{C}$ \# $\mathrm{search}=\% 22 \mathrm{RFID} \% 20$ cost $\% 20$ management $\% 22$
Mishra, P., Bolic, M., Mustapha, Y., \& Stewart, R. (2012). RFID technology for tracking and tracing explosives and detonators in minding services applications. Journal of Applied Geophysics, 76, 33-43. doi:10.1016/j.jappgeo.2011.10.004

Narsing, A. (2005). RFID and supply chain management: An assessment of its economic, technical, and productive viability in global supply chains. The Journal of Applied Business Research, 21(2), 75-80.

Roussos, G. A. (2008). Networked RFID, systems, software and services. London, UK: SpringerVerlag. doi:10.1007/978-1-84800-153-4

Sabbaghi, A., \& Vaidyanathan, G. (2008). Effectiveness and efficiency of RFID technology in supply chain management: Strategic value and challenges. Journal of Theoretical and Applied Electronic Commerce Research, 3(2), 71-81. doi:10.4067/S0718-18762008000100007

Sarac, A., Absi, N., \& Dauzere-Peres, S. (2009). A literature review on the impact of RFID technologies on supply chain management. Integrating the Global Supply Chain, 128(1), 77-95. Retrieved June 30, from http://citeseerx.ist.psu. edu/viewdoc/download?doi=10.1.1.169.7017\& rep $=$ rep $1 \&$ type $=$ pdf

Stevens, J., Weich, C., \& GilChrist, R. (2010). RuBee (IEEE 1902.1) - The physics behind, real-time, high security wireless asset visibility networks in harsh environments. Viable Assets, Inc. Retrieved from http://www.rubee.com/WhiteSEC/RuBee-Security-080610.pdf

Ustundag, A. (2010). Evaluating RFID investment on a supply chain using tagging cost sharing factor. International Journal of Production Research, 48(9), 2549-2562. doi:10.1080/00207540903564926

Veryfields.com. (2012). How do RFID tags work? Retrieved June 30 from http://www.veryfields.net/ how-do-rfid-tags-work 
Wamaba, S., \& Boeck, H. (2007). Enhancing information flow in a retail supply chain using RFID and the EPC network: A proof-of-concept approach. Journal of Theoretical and Applied Electronic Commerce Research, 3(1), 92-105.

Wamaba, S., \& Chatfield, A. (2009). A contingency model for creating value from RFID in supply chain network projects in logistics and manufacturing environments. European Journal of Information Systems, 18(6), 615-636. doi:10.1057/ejis.2009.44

Wang, M., Liu, J., Shen, J., Tang, Y., \& Zhou, N. (2012). Security issues of RFID technology in supply chain management. Advanced Materials Research, 2. Retrieved from http://www.scientific. net/AMR.490-495.2470

Ward, M., \& Kranenburg, R. (2006). RFID: Frequency, standards, adoption and innovation. JISC Technology and Standards Watch. Retrieved from http://www.jisc.ac.uk/uploaded_documents/ TSW0602.doc

Weinstein, R. (2005). IRFID: A technical overview and its application to enterprise. IT Professional, 7(3), 27-33. Retrieved from http://ieeexplore.ieee. org/xpls/abs_all.jsp?arnumber $=1490473 \&$ tag $=1$ doi:10.1109/MITP.2005.69

Whang, S. (2010). Timing of RFID adoption in a supply chain. Management Science, 56(2), 343-355. doi:10.1287/mnsc.1090.1121

\section{ADDITIONAL READING}

Abad, E., Palacio, F., Nuin, M., González de Zárate, A., Juarros, A., Gómez, J. M., \& Marco, S. (2009). RFID smart tag for traceability and cold chain monitoring of foods: Demonstration in an intercontinental fresh fish logistic chain. Journal of Food Engineering, 93(4), 394-399. doi:10.1016/j.jfoodeng.2009.02.004
Azevedo, S. G., \& Carvalho, H. (2012). Contribution of RFID technology to better management of fashion supply chains. International Journal of Retail \& Distribution Management, 40(2), 128-156. doi:10.1108/09590551211201874

Butz, C., \& Bogatu, C. (2008). Empirical study regarding the successful implementation of innovative information and communication technologies such as RFID into logistics processes. In Proceedings of the CIRP $15^{\text {th }}$ International Conference on Life Cycle Engineering, (pp. 406411). Sydney, Australia: CIRP.

Günther, O. P., Kletti, W., \& Kubach, U. (2008). RFID in manufacturing. Berlin, Germany: Springer-Verlag.

Kim, H. S., \& Sohn, S. Y. (2007). Production, manufacturing and logistics: Cost of ownership model for the RFID logistics system applicable to u-city. European Journal of Operational Research, 194(2), 406-417. doi:10.1016/j.ejor.2007.12.015

Kirankumar, G., Samsuresh, J., \& Balaji, G. (2012). Vehicle speed monitoring system (using rubee protocol). IACSIT International Journal of Engineering and Technology, 4(1).

Kyosuke, O., Tsuyoshi, T., Kenichi, Y., \& Osamu, T. (2009). An efficient and secure RFID security method with ownership transfer. In RFID Security, (pp. 147-176). Springer. Retrieved from http://www.springerlink.com/content/ pr16198625270834/

Lee, C. K. M., Ho, W., Ho, G. T. S., \& Lau, H. C. W. (2010). Design and development of logistics workflow systems for demand management with RFID. Expert Systems with Applications, 38(5), 5428-5437. doi:10.1016/j.eswa.2010.10.012

Meyer-Larsen, N., Lyridis, D., Müller, R., \& Zacharioudakis, P. (2012). Improving intermodal container logistics and security by RFID. International Journal of RF Technologies: Research \& Applications, 3(1), 15-38. 
Nativi, J. J., \& Lee, S. (2012). Impact of RFID information-sharing strategies on a decentralized supply chain with reverse logistics operations. International Journal of Production Economics, 136(2),366-377. doi:10.1016/j.ijpe.2011.12.024

Tsai, W.-C., \& Tang, L.-L. (2011). A model of the adoption of radio frequency identification technology: The case of logistics service firms: Creating competitive edge in operations and service management through technology and innovation. Journal of Engineering and Technology Management, 29(1), 131-151. doi:10.1016/j. jengtecman.2011.09.010

Will, T., \& Blecker, T. (2012). RFID-driven process modifications in container logistics: SOA as a solution approach. International Journal of Logistics: Research \& Applications, 15(2), 71-86. doi:10.1080/13675567.2012.674106

Wu, Y., Lirn, C. J., \& Cherng, T. (2011). RFID technology in emergency logistics: An exploratory study. International Journal of Management \& Enterprise Development, 11(2/3/4), 163-181.

Zacharewicz, G., Deschamps, J.-C., \& Francois, J. (2011). Distributed simulation platform to design advanced RFID based freight transportation systems. Computers in Industry, 62(6), 597-612. doi:10.1016/j.compind.2011.04.009
Zheng, M., Fu, C., \& Yang, M. (2012). The application used RFID in third party logistics. In Proceedings of the International Conference on Solid State Devices and Materials Science, (pp. 2045-2049). Physics Procedia.

\section{KEY TERMS AND DEFINITIONS}

Active RFID Tag: Tags which have an internal power source, which is able to transmit as well as receive information when in the vicinity of a reader.

E-Enablement: The ability to use Information and Communication Technologies (ICTs) to integrate various systems and processes, for the purposes of dynamically sharing and distributing information relating to specific tasks and operations.

Passive RFID Tag: Tags which do not have an internal power source, and as a result rely on a reader to power it up in order to enable the transmittal of date and information stored within it. The advantages of passive tags over active tags include lower cost and smaller size.

Radio Frequency Identification (RFID): A type of information and communication technology which has the ability to identify, record, verify, and/or process tangible items, intangible processes, people and operations. It has a wider use in inventory management and control, such as tracking and security, and is particularly suited to logistics and supply chain related operations. 